\title{
UMA ANÁLISE DA CONDIÇÃO DOS REFUGIADOS SÍRIOS À LUZ DA DIGNIDADE DA PESSOA HUMANA
}

\section{AN ANALYSIS OF THE CONDITION OF SYRIAN REFUGEESIN THE LIGHT OF THE DIGNITY OF THE HUMAN PERSON}

\author{
Marielle Spindola $^{1}$
}

Resumo: A pesquisa em foco aborda tema de grande relevância na atualidade: a condição dos refugiados face ao conflito que atinge a Síria, desta feita, o objetivo precípuo do trabalho é investigar sobre a situação de aludidos refugiados e a migração deste povo, que se tornou uma problemática no cenário internacional. Em específico,tratou-se a celeuma que atinge os refugiados sírios frente à dignidade da pessoa humana, principalmente em virtude da migração forçada, já que estes são constrangidos a deixar seus lares devido aos conflitos bélicos que assolam aquele seu país. A pesquisa se caracteriza como bibliográfica e de abordagem qualitativa. Para tanto, tratou-se de identificar sucintamente aspectos históricos e, em seguida, esclareceu-se sobre o conceito de refugiado, assim como da legislação que lhe protege, aliás, buscou-se identificar os aspectos que contribuem para degradar a vida humana e a violação da dignidade e, por fim, constatou-se a substancial violação de direitos, especialmente aqueles relacionadas à dignidade da pessoa humana, à vista das condições que lhes foram propiciadas pelo conflito em âmbito sírio.

Palavras - chave: Dignidade da Pessoa Humana; Refugiados; Sírios.

Abstract: The research in focus approaches a topic of great relevance nowadays: the condition of refugees in the face of the conflict that afflicts Syria. It has as objective forehead approaches the situation of alluded refugees and the folk migration, which became a problematic of the current international scenario. Specifically, was treated the issue which affects Syrian refugees facing the dignity of the human person, with the forced migration, where they are constrained to leave their home because of

1 Graduada em Direito pela Faculdade CNEC de Joinville (FCJ), aluna do Módulo I da Escola Superior da Magistratura do Estado de Santa Catarina (ESMESC), extensão de Joinville - SC. Email: spindolamarielle@gmail.com. 
war conflicts. This research is characterized by the bibliographical and qualitative approach. Therefore, the historical aspects were succinctly identified and then, was enlightened about the concept of refugee and the legislation that protect him. In addition, was sought to identify the aspects that contribute to degrading the human life and the dignity violation. At least, was verified the substantial violation of rights, especially of the dignity of the human person, in view of the conditions that had been afforded them by the Syrian conflict.

Keywords: Dignity of the Human Person; Refugees; Syrian.

\section{INTRODUÇÃO}

Nesta pesquisa será promovida uma análise acerca da dignidade humana dos refugiados sírios e da migração de povos, que se tornou uma problemática do cenário internacional. Para um entendimento mais preciso, inicia-se com uma breve contextualização história acerca da guerra, em específico sobre o conflito na Síria, que teve início com a Primavera Árabe e prossegue até a atualidade. Tratar-se-á, em seguida, sobre os refugiados, bem como acerca da legislação pertinente à proteção destes e o papel do Alto Comissariado das Nações Unidas (ACNUR), órgão internacional que atua como fiscal e protetor dos direitos dos refugiados. E, ao final se buscará esclarecer os aspectos afeitos à observância da dignidade da pessoa humana dos refugiados sírios.

\section{CONTEXTUALIZAÇÃO HISTÓRICA}

A guerra antecede o surgimento do Estado, suas origens são tão remotas quanto a história da humanidade. Em decorrência da evolução humana, as guerras também se modificam e revestem de novas características, no entanto continuam a modificar a história. Ora, foram causadoras da derrubada de impérios e declínio de Estados, enquanto que algumas contribuíram para o desenvolvimento cientifico, assim como também para grandes desastres e massacres da história da humanidade 
Conforme Ahlert e Almeida, é posta uma aflição no que se diz respeito ao conceito de refúgio: "O refúgio é e se manterá sendo tema preocupante a nível social e governamental, especialmente por se verificar o aumento do número de pessoas que buscam este recurso para manterem a sua sobrevivência." (AHLERT; ALMEIDA, 2016, p. 01).

Souza et al. (2017, p. 02-03) apresenta um grande marco após a Primeira Guerra Mundial:

Após a Primeira Guerra Mundial, o que aconteceu foi o surgimento de vários países na região que antes pertencia ao Império Otomano. Países estes, controlados por governantes de confiança da França e do Reino Unido para que estes pudessem atuar como quisessem na região, principalmente na extração do petróleo. Dentre estes países, encontra-se a Síria. No entanto, a Síria, sob o comando francês, por não apresentar reservas satisfatórias, foi vendida para companhias estrangeiras e mantida sob seu controle até a Segunda Guerra Mundial. Terminada a Segunda Grande Guerra, os estrangeiros foram expulsos de todos os novos pequenos países, inclusive da Síria. Porém, antes desta retirada, criaram o Estado de Israel, o que passou a ser uma das causas de conflito na região. Enquanto todos estes conflitos ocorriam, a Síria passou por um grande período de instabilidade, com golpes de Estado e o surgimento de uma nova ideologia, chamada Baath. Esta ideologia une o antigo desejo de uma nação unicamente árabe, com ideais socialistas e laicos. Desta forma, chega ao poder, Hafez al-Assad. Com o início da Guerra Fria, e a divisão ideológica do mundo entre os Estados Unidos da América e a União das Repúblicas Socialistas Soviéticas, inicia-se um período muito movimentado na Síria, em que também surge uma oposição ao governo al-Assad, a chamada Irmandade Muçulmana.

Não obstante ser um Estado laico, al-Assad é alauíta, uma corrente, mais acanhada, oriunda dos xiitas, que dá apoio a este. Contudo mais da metade da população é sunita, fato que faz 
com que a Irmandade Muçulmana venha a iniciar uma revolta armada contra o governo. Com isso, a atitude do presidente foi uma resposta violenta, que ocasionou a morte de milhares de civis, e múltiplas prisões. No ano 2000, Al- Assad faleceu e seu filho, Bashar al Assad assume o governo. Bashar, com as inúmeras pressões presentes no momento, traz uma onda de esperança para o povo sírio, concebendo libertações de presos, além de liberar o acesso à internet. Porém, retorna a Irmandade Muçulmana e após anos de debates políticos, a oposição é presa, tornando então a Síria um país do "eixo do mal", segundo o presidente americano George W. Bush. (SOUZA et al, 2017).

Em 1916, a França e a Grã-Bretanha, no âmbito de negociações secretas que contaram com representantes de cada um dos lados, os diplomatas François Georges-Picot e Sir Mark Sykes, haviam dividido já, entre si, o território. O acordo Sykes-Picot, nome pelo qual ficou conhecido, definiu as fronteiras da atual Síria a régua e esquadro, entregando-a ao governo francês. Quatro anos mais tarde, 1920, o acordo franco-britânico passou à prática e foi formalizado pela Liga das Nações, no âmbito do sistema de mandatos. O mandato da Síria que incluía também o Líbano e a província de Hatay foi atribuído à França. Estava-se então a 29 de Setembro de 1923. (SANTOS, 2014).

Santos (2014, p. 05), discorre sobre a independência da Síria:

A 17 de Abril de 1946, a Síria tornou-se independente. Fechavam-se 26 anos de subordinação à França. Do ponto de vista político, o período pós-independência foi particularmente instável. Os interesses distintos dos diferentes grupos étnicos, religiosos e ideológicos (socialismo, pan-arabismo, batismo, por exemplo) do país num espaço de poder nacional novo, pronto a ser conquistado e com todas as oportunidades para ser redesenhado, geraram tensões significativas entre os partidos já existentes aos quais o poder respondeu sempre com uma presença militar forte e coesa, entendida como a única forma de manter a lei e a ordem desejada. A prevalência do papel do exército e de forças de segurança 
assim como a disputa sectária pelo poder é ilustrada pelo número de golpes de Estado - sete, entre 1949 e 1970, tendo o último marcado o início do Regime al Assad, com a ascensão de Hafez al-Assad, no contexto da chamada Revolução Corretiva de Novembro, um golpe que visava derrotar a facção dominante ultra-esquerdista do partido Baath.

A Síria, situada no Oriente Médio, enfrenta, desde 2011, uma guerra civil que já deixou milhares vítimas e refugiados. Tem-se a informação de que, no mínimo, ocorreram 130 mil mortes, além de ter o conflito gerado uma expressiva crise humanitária, que abalou toda a infraestrutura existente no país. Importa acrescentar que todo o conflito teve início com protestos denominados e conhecidos como a "Primavera Árabe"(FURTADO; RODER; AGUILAR, 2014).

A chamada Primavera Árabe ficou conhecida como:

[...] propulsora e desencadeadora de movimentos políticos internos, em alguns Estados da África e do Oriente Médio. $\mathrm{Na}$ exposição desse episódio, esse estudo conta com relatórios realizados por pesquisadores do Centro de Estudos Estratégicos da África, dos Estados Unidos da América, e artigos de professores especializados em Oriente Médio para dissertar sobre as causas e consequências das manifestações nos principais países atingidos pela Primavera Árabe. (FURTADO; RODER; AGUILAR, 2014, p.05).

Por conseguinte, a Primavera Árabe deu luz a outros movimentos revolucionários dos povos árabes, que se impuseram contra poderes ditatoriais que estavam em posição dominante há muitos anos. De início, estes movimentos eram de caráter liberal e laico, e compreendiam os seguintes países: Jordânia, Líbia, Egito, Iêmen, Tunísia, Argélia, Bahrein, Marrocos e Síria, que viviam sob a ditadura, e que, por intermédio das redes sociais, mobilizaram-se e organizaram os protestos. (NASCIMENTO, 2011).

De acordo com os ensinamentos de Furtado, Roder e Aguilar 
(2014), estes protestos serviram e deram lume a outros desafios. Iniciou-se uma verdadeira guerra civil no país, visto que:

[...] serviram de inspiração e exemplo para ativistas e civis desafiarem a ditadura no comando do país. O presidente Assad se recusou a renunciar, porém, fez concessões, encerrando o estado de emergência, que durava 48 anos, aprovou uma nova Constituição e realizou eleições multipartidárias, mas a oposição continuou combatendo e exigindo sua queda. (FURTADO; RODER; AGUILAR, 2014, p. 01).

Quanto aos motivos da guerra civil, Furtado, Roder e Aguilar (2014, p. 01) afirmam que estão assentados de modo profundo na história. No início da criação do Estado Sírio, “[...] independente em 1946, a disputa étnica e religiosa pelo poder esteve sempre em evidência, como consequência da política colonial francesa de enfraquecer a unidade árabe, instaurando pequenas divisões no país".

Comandadas por um grupo chamado de alauítas, que representava a minoria da população, em desvantagem da maioria Sunita. Nesta guerra, ocorreu a influência de grupos diversos, o que fez com que o conflito tomasse uma proporção que impossibilitou definir os envolvidos, ao passo que seu advento "reviveu antigas tensões entre o Ocidente e o Oriente." (FURTADO; RODER; AGUILAR, 2014, p. 02).

Para um mais completo esclarecimento, importa mencionar que, na década de 60, ocorreram dois golpes de Estado que favoreceram o grupo alauítas, que além de não representar a maioria do povo, era o grupo do presidente Bashar al-Assad, que mantinha um forte regime ditatorial, mediante a restrição de liberdades e a repressão, de forma violenta, daqueles considerados como ameaça à segurança nacional, o que motivou o povo a querer derrubar o governo. (FURTADO; RODER; AGUILAR, 2014).

Importa esclarecer que o problema na Síria não se baseia 
somente na manutenção do poder ou da ditadura histórica, muito menos na vitória de democratas. Neste conflito há tantos atores que é dificultoso saber os reais objetivos e interesses. No entanto, pode-se tratar o conflito como um " [...] conflito entre arqui-inimigos religiosos, de interesses estratégicos de Israel, da guerra contra o terror e da tentativa da União Europeia de encontrar seu palco diplomático internacional". Desta forma, os interesses do povo da Síria vêm em outro plano. (CAMPOS, 2013, p. 33-34).

Ocorreram ainda intensas manifestações das Nações Unidas, nos Estados Unidos da América e na União Europeia, que defendiam a instauração da democracia naquele país, paralelamente ao anseio de que o presidente sírio deixasse o cargo. No entanto, Assad, continuou no poder, mesmo em situação extremamente delicada, diante da continuidade dos protestos dos rebeldes. (DUTRA, 2017).

Sobre o tema, explica-se:

Em escala global, desde o início do conflito a ONU tem realizado esforços condenando o governo de Bashar Al-Assad. Todavia, ações práticas ocorreram somente em abril de 2012, com uma missão de observação aprovada pela Resolução n. 2042, depois de uma série de declarações do Conselho de Segurança (CS) para que se pusesse fim à violência e ao desrespeito aos Direitos Humanos. Uma equipe de 30 observadores militares tinha por objetivo monitorar o cessar fogo no país e a retirada de armas das áreas civis. (FURTADO; RODER; AGUILAR, 2014, p. 02).

Não obstante, Santos (2014, p. 18) discorre sobre o uso de armas químicas:

A 21 de Agosto 2013, ativistas sírios e líderes da oposição afirmam que o governo usou armas químicas matando centenas de pessoas nos subúrbios de Damasco. Bashar a-Assad deu por certo tratarem-se de acusações sem qualquer sentido e apontou a autoria dos ataques aos grupos 
rebeldes que, em resposta, negaram o uso ou sequer a posse de tal armamento. A 23 de Julho de 2012, o governo havia já confirmava implicitamente a posse de um arsenal de armas químicas produzidas e guardadas mas apenas para um eventual ataque de forças externas. O porta-voz do Ministro dos Negócios Estrangeiros, Jihad Makdissi, garantia também que "em nenhuma circunstância, seriam usadas contra o povo sírio ou contra civis". Após quatro meses de conversações do suposto primeiro ataque, o regime de Assad aceitou, em julho de 2013, o envio de inspetores para o terreno a fim de investigar o alegado recurso a armas químicas. A missão, autorizada pelo Secretário-Geral da ONU e coordenada por AkeSellstrom, confirmou que tinham sido utilizadas armas químicas em grande escala, mas não identifica quem as usou.

Ademais, foram divulgados relatórios sobre crimes, torturas, assassinatos e diferentes violações dos direitos humanos, praticadas pelo governo, como também pelos grupos rebeldes. Diante disso, tentou-se a aprovação de resoluções para impor sanções à Síria pelo ocorrido. No entanto, os membros do Conselho de Segurança permaneciam divididos diante de uma possível intervenção militar resultante dos termos das resoluções, algo que Rússia e China, membros permanentes e aliados de Assad, se mostravam impassíveis, utilizando do seu poder de veto para impedir ações mais drásticas. (FURTADO; RODER; AGUILAR, 2014).

Enquanto isso, com o aumento da quantidade de refugiados, o Alto Comissariado das Nações Unidas para Refugiados (ACNUR) iniciou amparo e distribuição de ajuda humanitária à população síria. Entrementes, no ano de 2013,o número de refugiados chegou a 2 milhões de pessoas, o que sobrecarregou os países receptores: Iraque, Jordânia, Líbano e Turquia. (FURTADO; RODER; AGUILAR, 2014).

Importante esclarecer que a ACNUR foi criada com o intuito de: 
[...] enfrentar a problemática que envolve o número elevado de pessoas que precisam de amparo e que não podem mais contar com a proteção de seus países de origem. $\mathrm{O}$ ACNUR trabalha para garantir a permanência do refugiado em determinado Estado, com autorização do país em que foi recebido, inclusive busca auxiliar os refugiados a obter subsídios materiais até que consiga ter as condições mínimas para sua manutenção no país em que foi abrigado. (AHLERT; ALMEIDA, 2016, p. 02).

Portanto, após esclarecer a respeito do contexto histórico do conflito na Síria, em consequência da Primavera Árabe, que culminou numa guerra civil que perdura há muito tempo, onde um governo minoritário está no poder e vitimiza muitas pessoas, se faz importante elucidar questões afeitas aos refugiados e seus direitos.

\section{O REFUGIADO, A LEGISLAÇÃO E A ACNUR}

Conforme o dicionário da língua portuguesa, refugiado é aquele que "tomou refúgio, que se refugiou. [...] ou quem é forçado a abandonar o seu país por motivo de guerra, desastre natural, perseguição política, religiosa, étnica, etc." (DICIONÁRIO, 2017).

Destarte Reis e Menezes (2012, p. 17) afirmam que:

Consequentemente, é possível compreender que o instituto do refúgio busca, sim, reparar uma situação de violação de direitos humanos para garantir que o indivíduo - conforme consta na DUDH - goze de liberdade de palavra, de crença e que esteja a salvo do temor da perseguição. Nesse sentido, podemos sustentar que o reconhecimento como refugiado visa corrigir uma situação específica de violação de direitos humanos: aquela materializada em forma de perseguição. Isso não significa afirmar que toda violação de direitos humanos equivale à perseguição, pois outros elementos da definição devem ser considerados para que se caracterize a condição de refugiado, notadamente o caráter discriminatório da inflição do dano - o qual se baseia em conside- 
rações de raça, religião, nacionalidade, opinião política ou grupo social - e o cruzamento de fronteiras internacionais. Tais entendimentos possibilitam a concretização de um processo de determinação do status de refugiado que fuja das limitações que tentam minar tal proteção devido a interesses que negligenciam o caráter forçado do movimento e os prejuízos que nele resultam e que dele são originados. Ou seja, resulta uma compreensão sobre o refúgio que está de acordo com o desenvolvimento histórico do regime internacional dos refugiados.

\section{O Estatuto dos Refugiados (1951) os define como:}

[...] as pessoas que se encontram fora do seu país por causa de fundado temor de perseguição por motivos de raça, religião, nacionalidade, opinião política ou participação em grupos sociais, e que não possa (ou não queira) voltar para casa. Posteriormente, definições mais amplas passaram a considerar como refugiados as pessoas obrigadas a deixar seu país devido a conflitos armados, violência generalizada e violação massiva dos direitos humanos. (ACNUR, 2017).

Importa pontuar que a Convenção acima mencionada consolida e fornece a legislação sobre os direitos do refugiado. Determina medidas básicas para o tratamento de refugiados, todavia, impõe limites para que os Estados possam desenvolver esse tratamento. igual forma, traz que o refugiado tem direito a asilo e segurança, bem como os mesmos direitos do estrangeiro que reside no país, e incluem-se aqui direitos fundamentais inerentes a qualquer indivíduo. Desta forma, os refugiados dispõem de direitos civis básicos incluindo a autonomia de pensar, a independência de locomover-se e a não sujeição à tortura e a tratamentos degradantes. Também, a Convenção destaca que não deve haver discriminação por raça, religião, sexo ou país de origem, e estabelece ainda que o refugiado não possa ser devolvido ao seu país de origem, ou melhor, não pode ser expulso. (ACNUR, 2017).

Após algum tempo, ocorreram situações diversas gera- 
doras de novos conflitos, o que sugeriu novas providências em relação aos refugiados. Logo em 1967, foi assinado um protocolo e transmitido aos Estados. No entanto, tem-se que a Convenção e o Protocolo são os principais dispositivos internacionais que rezam sobre a proteção dos refugiados e seu objeto é reconhecido internacionalmente, sendo ratificado por vários Estados. Inclusive, sua "[...] ratificação também tem sido recomendada por várias organizações, tal como o Conselho da União Europeia, a União Africana e a Organização dos Estados Americanos." (ACNUR, 2017).

Implica saber que o Brasil pactuou internacionalmente a proteção aos refugiados a datar da ratificação da Convenção de 1951 e do Protocolo de 1967, sobre o Estatuto dos Refugiados. Conta o país, ainda, em sua legislação pátria, com a Lei $\mathrm{n}^{\circ}$ 9.474 de 1997, que dispõe em específico sobre a questão dos refugiados. (MENDES, 2017).

Embora entenda a Convenção de 1951 e o Protocolo de 1967 como instrumentos de direitos humanos, Reis e Menezes (1998 apud Steinbock, 2012, p. 73) sustentam que:

Os padrões amplos de direitos humanos não devem ser utilizados diretamente para conformar o entendimento dos elementos da definição de refugiado. Mais especificamente, ele afirma que somente alguns direitos humanos podem ser entendidos como constituindo a estrutura para a interpretação da Convenção. Justificando esse entendimento, o autor destaca o fato de que a Convenção menciona vários dos direitos humanos que haviam sido recentemente enunciados na DUDH, mas não todo esse rol de direitos. Dessa forma, após analisar o texto, a história e o contexto da Convenção, Steinbock (idem) conclui que a definição de refugiado centra nos princípios de não discriminação, condenação da culpa coletiva e proteção da liberdade de pensamento e expressão - servindo, portanto, aos propósitos identificados, para proteger importantes direitos humanos, mas não sendo coextensivos ao completo conjunto de direitos humanos. 
Segundo Souza et al. (2017, p. 09):

De acordo com alguns parlamentares, o mundo observa a fuga em massa dos sírios por sobrevivência. Nesse contexto, a Europa se divide entre países que abrem suas fronteiras em nome dos direitos humanos e países que se preveem de possíveis danos as suas soberanias e seus nacionais. Frente a esse impasse, o Brasil mantém uma postura acolhedora, mesmo com mais de dez mil quilômetros de distância entre os países, os sírios já representam 2252 refugiados até o primeiro semestre de 2016. Segundo o Deputado Eduardo Barbosa (PSDB-MG), é um direito das pessoas de sair de locais onde a loucura impera, pois não é saudável viver em um ambiente de guerra.

Conforme apresentado por Souza et al. (2017, p. 10):

Atualmente, o governo federal realiza a triagem dos sírios por meio do CONARE - Comitê Nacional para os Refugiados, vinculado ao Ministério da Justiça, que também reúne segmentos representativos da sociedade civil e das Nações Unidas (ACNUR). Tem por finalidade analisar e decidir todos os pedidos de refúgio no Brasil, além de criar normas que esclareçam os termos da lei de refúgio (Lei no 9.474/97). Após decisão positiva pelo CONARE, o refugiado levará uma copia do Diário Oficial para ser registrado junto ao Departamento de Policia Federal e solicitar a Cédula de Identidade de Estrangeiro (CIE) e o Registro Nacional de Estrangeiros (RNE). Além disso, o refugiado terá direito a uma carteira de trabalho provisória e adquire os mesmos direitos de qualquer outro estrangeiro em situação regular no Brasil.

Por conseguinte, é do Alto Comissariado das Nações Unidas a competência para a efetivação dos instrumentos de proteção do refugiado, bem como supervisionar o seu cumprimento. É evidente que “[...] ao ratificar a Convenção e/ou o Protocolo, os Estados signatários aceitam cooperar com o ACNUR no desenvolvimento de suas funções e, em particular, a facilitar a função específica de supervisionar a aplicação das provisões" 
contidas nestes instrumentos. (ACNUR, 2017).

Sendo assim, a Convenção de 1951, e o Protocolo de 1967, são os meios que garantem a qualquer pessoa que necessiteexercer o direito de buscar refúgio em outro país.

\section{DA DIGNIDADE DA PESSOA HUMANA DOS REFUGIADOS SÍRIOS}

Para Immanuel Kant, a dignidade é o valor de que se reveste aquilo que não tem preço, ou seja, que é insubstituível por algo ou alguém. Isto posto, pode-se dizer que a dignidade humana é uma qualidade intrínseca ao ser humano, individual e insubstituível (KANT, 2004).

De acordo com a dignidade humana, é possível subentender que todas as pessoas têm dignidade e são equitativamente dignas. Isto indica a inviabilidade de se reduzir as situações de vida do ser humano a um nível, que cause seu desgaste ou à sujeições de vida de extrema carência ou de seu aproveitamento perante à situação que se encontra . Em síntese, o princípio defende que cabe ao direito o dever de coibir e impedir que a pessoa viva em situação indigna.No que tange aos refugiados, da dignidade da pessoa humana depreende-se que o refugiado tenha condição mínima de liberdade e existência para o início de uma nova vida. (AHLERT; ALMEIDA, 2016).

Na celeuma em questão, tem-se que a maioria das pessoas pode confiar nos seus governos para garantir e proteger os direitos básicos e a sua segurança física. Porém, no caso de conflitos ou guerras, o país de origem demonstrou ser incapaz de garanti-los. E, neste caso, ao ACNUR é atribuído o papel de assegurar que qualquer pessoa, em caso de necessidade, possa exercer o direito de buscar e obter refúgio em outro país e, caso deseje, regressar ao seu país de origem. (AHLERT; ALMEIDA, 2016). 
No entanto, em se tratando de guerra, surgem vários problemas, dentre eles a migração de um grande número de pessoas. Disto decorrem consequências sérias, tanto ao local de onde ocorrem os conflitos como de pessoas fugindo, como também ao local onde estão se refugiando. Apesar das dificuldades encontradas em diversos locais do mundo, a busca de refúgio tem aumentado significativamente, embora o que buscam os refugiados é uma nova vida, longe das ameaças e perigos ao quais estavam sujeitos no país de origem. (GUERRA, 2014).

Em 2011, a Organização das Nações unidas (ONU) criou uma comissão a fim de monitorar os direitos humanos na Síria. Em 2013, esta comissão apresentou um relatório que acusou que os dois lados do conflito cometerem crimes de guerra contra a humanidade. O relatório informou que são 2,8 milhões sírios dentro do país que vivem em condição de risco de vida. Também, recolheu informações sobre massacres contra civis, uso de bombas proibidas, bombardeios a hospitais e escolas, além das torturas, execuções e seqüestros. (CAMPOS, 2013).

De acordo com Garcia (2016), que integra o ACNUR, o conflito na Síria, desencadeou a maior crise humanitária de refugiados do tempo atual, a qual é causadora de sofrimento para milhões de pessoas e que deveria atrair o apoio de todo o mundo.

A soberania territorial da Síria foi violada durante a guerra civil. Diversos grupos armados não estatais ocupam grande parte do território sírio agravando ainda mais a violência no país. Ademais, "Os civis são vítimas constantes do uso de bombas de fragmentação, que resulta em mortes, lesões e em um legado de remanescentes explosivos de guerra." (GARCIA, 2016).

Inclusive, campos de refugiados são vítimas de bombardeios, mesmo que o ataque a estes locais constitua crime de guerra porque viola os princípios e direitos previstos no "Protocolo II Adicional às Convenções de Genebra, de 12 de 
Agosto de 1949, relativo à Proteção das Vítimas dos Conflitos Armados Não Internacionais". O art. $4^{\circ}$ do citado Protocolo dispõe que todos os civis devem ser respeitados e protegidos, além de proibir atentados contra a vida, bem estar físico ou mental e saúde das pessoas. Veda, atos de terrorismo, atentados à dignidade da pessoa $\mathrm{e}$ "[...] os tratamentos humilhantes e degradantes, a violação, a coação à prostituição e todo o atentado ao pudor." (GARCIA, 2016).

Diante do exposto, aduz Garcia (2016) que:

Vários artigos da Declaração Universal de Direitos Humanos foram violados, tais como os arts. 2,3, 5,9 e 25. O relatório mundial de 2015 que aborda acontecimentos de 2014 da Human Rights Watch trouxe alguns dados que comprovam as violações. Segundo o relatório, a Rede Síria de Direitos Humanos destacou a possibilidade de que 85.000 sírios estivessem submetidos a desaparecimento forçado (subtração forçada de alguém de seu âmbito familiar e social de forma ilegal) pelo governo. Tal afirmação fere o direito à paz, à liberdade e à dignidade do homem e também à Declaração sobre a Proteção de Todas as Pessoas contra os Desaparecimentos Forçados de 1992.

O ACNUR demonstra ainda preocupação em relação ao crescimento do número de sírios buscando segurança na Europa, desde os riscos que enfrentam nas fronteiras até o estabelecimento no território receptor. Em relação aos refugiados que chegam à Itália, a grande maioria continua a procura de refúgio em países vizinhos. Há de se relatar, também, a quantidade de crianças desacompanhadas, que os pais enviaram com parentes ou amigos e não puderam se juntar a eles, devido ao valor da viagem. (ACNUR, 2017).

Ainda importa apresentar que: "A principal rota de entrada destes imigrantes para a Europa é pelo mar Mediterrâneo, principalmente Itália e Grécia”. Pontua a Organização Internacional para Migração (IOM) que, no ano de 2015, 1 milhão dos 
refugiados chegaram pelo mar. (AMAL, 2017).

Reconhece, ainda, a ACNUR que além do problema da viagem dos refugiados, os países receptores são diretamente afetados na sua infraestrutura e recursos, que refletem diretamente a qualidade de vida e a própria dignidade da pessoa humana. (ACNUR, 2017).

Neste sentido, esclarece Amal (2017) que:

Muitas são as razões que explicam por que a crise dos refugiados na Europa tenha se agudizado em 2015. Pode-se arguir que houve um esgotamento da possibilidade de absorção daquela população por países vizinhos como Irã, Jordânia e Líbano no Oriente Médio e Marrocos, Argélia e outros no norte da África; ou, que houve uma deterioração das já péssimas condições socioeconômicas que levaram inicialmente ao levante da Primavera Árabe nos países de origem dos refugiados; que se intensificaram os bombardeios da Rússia na Síria, inclusive em áreas civis; que o autointitulado Estado Islâmico aumentou seu poder de forma a possuir grande extensão do território sírio e iraquiano e grande inserção na Líbia. Na verdade, podemos dizer que todos esses fatores contribuíram para que se constituísse uma gigantesca onda de milhões de refugiados na faixa temporal de um ano.

A maioria dos refugiados está à espera na Grécia e Itália por asilo em outros países europeus. A Hungria, Alemanha, Suécia, Noruega, Áustria, França, Espanha, etc., encontramse na lista dos que recebem e abrigam a maior quantidade de imigrantes. A Alemanha foi a que mais recebeu imigrantes, e dentre eles Sírios. (AMAL, 2017).

Esse processo se deu em meio ao ápice da crise com maior chegada de pessoas em julho e agosto de 2015, quando então Ângela Merkel decidiu abrir as fronteiras para a entrada dos refugiados, a chamada de "política de portas abertas". Esta atitude da chanceler, entretanto, durou pouco tempo, sendo aos poucos substituída por uma série de outras medidas para trancafiar a população síria dentro do país em guer- 
ra. Contudo, ela foi suficiente para gerar grande desgaste ao seu governo, seja devido aos ataques sofridos pelos setores mais à direita, seja devido ao fato de a população absorver cada vez mais ideologias xenofóbicas, racistas e islamofóbicas, frente à crise da União Europeia. (AMAL, 2017).

Em 2016, ocorreu uma depressão na recepção de refugiados na Alemanha, por conta de Merkel ter acordado com o presidente da Turquia a interrupção da entrada de sírios por meio das fronteiras turcas. A fim de impedir o acesso dos refugiados, a Turquia construiu um enorme muro em sua fronteira com a Síria, impedindo assim a passagem terrena. E "qualquer um que se aproximar do muro é recebido com uma chuva de tiros, fato que vem sendo denunciado por organizações de defesa dos direitos humanos, mas que são simplesmente ignorados pela União Europeia e seus membros." (AMAL, 2017).

Interessa saber que hoje vivem na Turquia aproximadamente:

[...] 3 milhões de sírios, que é uma quantidade equivalente à totalidade de refugiados que entraram na União Europeia desde o começo da crise. Atualmente, apenas uma em cada mil tentativas de entrar no país alcançam sucesso. Além disso, como parte do acordo, a Turquia também previne a chegada de embarcações com refugiados nos portos gregos, principal meio de entrada na Europa até então. (AMAL, 2017).

Em fevereiro de 2017, os líderes da União Europeia se reuniram para comunicar um pacote com dez medidas contra a imigração ilegal. Dentre essas medidas tem-se o estímulo ao retorno para cidade natal, que chamaram de repatriação voluntária. (AMAL, 2017).

Amal (2017) defende que o Estado age, por meio de seu governante, relevando somente o seu interesse e benefício próprio, e deixa de analisar o desenvolvimento da sociedade como um todo. Desta forma, exclui o ser humano de ter uma 
condição digna de vida, e não se manifesta para a solução da injustiça social.

\section{CONCLUSÃO}

A pesquisa aqui concluída teve como objetivo esclarecer aspectos afeitos à dignidade da pessoa humana dos refugiados sírios. Para um mais amplo entendimento acerca da temática, foi necessário um breve explanar histórico referente ao conflito, seguindo com a celeuma que integra a questão.

Além de utilizar-se o tema refugiado para configurar a pessoa que foge de seu país em virtude do temos de perseguições preconceituosas e discriminatórias, há também os motivos econômicos, que podem ser caracterizados pela escassez de água, alimentos e outros mantimentos necessários para a manutenção da vida humana.

Importa pontuar que, em consequência da Primavera Árabe, culminou uma guerra civil na Síria que perdura há muito tempo, onde um governo minoritário está no poder e continua comprometendo a vida de muitas pessoas.

As causas já estavam de certo modo presentes, e o descontentamento em vários países era já disfarçado, pela comum falta de emprego e oportunidades para as gerações mais jovens, além da repressão política e a concentração de poder e riqueza na mão de poucos.

Foram cometidos múltiplos erros de avaliação sobre o rumo da revolta na Síria. O primeiro foi pensar que o governo de Bashar al-Assad cairia facilmente, como na Tunísia ou no Egito. O segundo foi imaginar que isso traria a paz e a democracia à Síria. O terceiro foi posicionar-se politicamente ao lado dos interesses dos Estados árabes sunitas ricos do Médio Oriente, aliados dos Estados Unidos e também da Turquia.

Hoje é fácil ver as consequências desastrosas desses erros 
para a União Europeia, cujos interesses não coincidem, necessariamente, com os dos Estados Unidos na região. A Síria tornou-se um campo de batalha pela supremacia no Médio Oriente, entre teocracias sunitas e xiitas, luta na qual os europeus nada têm a ganhar.

Os múltiplos grupos islamistas que combatem na guerra civil da Síria, tipicamente oriundos dos sunita, têm sido apoiados, direta ou indiretamente, pela Arábia Saudita, Turquia, entre outros.

O resultado foi intensificar o conflito e as vagas de refugiados. A guerra civil da Síria atingiu a dimensão atual não apenas pela inquestionável violência e repressão punitiva das tropas de Bashar al-Assad.

Ultimamente, é a extrema barbárie dos islamistas o principal causador de destruição e fuga em massa das populações, sejam minorias religiosas, ou étnicas, ou até dos próprios muçulmanos sunitas que não se reveem nesse totalitarismo islamista.

Por diversas ocasiões, campos de refugiados foram alvejados por bombardeios, ataques que configuram substanciais e inadmissíveis violações a princípios e direitos. São, em suma, crimes de guerra, em consequência dos quais milhares de pessoas perderam a vida e outros tantos, paralelamente ao conflito, vivem num contexto de calamidade, especialmente os que deixaram seus lares em busca de refúgio nos países vizinhos.

Sabe-se que o conflito na Síria desencadeou uma grave crise humanitária, causadora de sofrimento para milhões de pessoas que de alguma forma tentam se proteger buscando proteção em acampamentos de refugiados ou em países vizinhos. Além das situações de terror, pressão e precariedade às quais foram sujeitados no local dos conflitos, ou na embalada travessia para o local onde seriam recebidos como refugiados, convivem, dado o exposto, também com o descaso. 
Diante desse cenário de plena desorganização política e ataque aos direitos humanos dos cidadãos sírios, torna necessário acreditar no papel das Organizações Internacionais como instrumentos institucionais reguladores da realidade internacional.

Bastante se espera desses organismos, principalmente, no que relaciona-se ao humanitarismo, à forma de tratar a relação conflituosa existente e os refugiados oriundos da guerra.

Entretanto, há um embate quanto à ação desses agentes, que seria a dificuldade da discussão sobre a soberania dos Estados $\mathrm{e}$, na maioria das vezes, o intervencionismo perde essa guerra para o domínio reservado do Estado, tendo como único ato de atuação a indireta, exceto quando interesses econômicos estratégicos estão em jogo. Infelizmente, a interferência de países externos tem complicado gradualmente a situação na região.

Até então existente "Guerra Fria" continua a ocorrer no apoio que Estados Unidos e Rússia têm demonstrado na Síria e no Oriente Médio como um todo. A convivência pacífica entre esses dois polos de poder sempre esteve como primeira opção, em especial por ambas possuírem as chamadas armas de destruição em massa.

Nesse sentido a disputa da região sempre se deu por jogo de influência e financiamento indireto. Salienta ainda que o fator geopolítico historicamente mais importante dessa região é o fato dela ser possuidora de petróleo suficiente para abastecer os países aliados dessas superpotências, revelando o aspecto econômico por trás da luta pela supremacia global.

Foi possível verificar que a estrutura de alguns países receptores foi drasticamente abalada, como foi o caso da Turquia, que recebeu mais de 2 milhões de refugiados. Desta feita, outros países da Europa passaram a receber também refugiados, mas sucede que após certo tempo diversas nações, como a Alemanha, por questões políticas, passaram a limitar a chega- 
da de novos refugiados.

Corrobora-se que o direito de refugiar-se em que estas pessoas tanto lutam para adquirirem, ou apenas para dar uma vida digna a seus familiares, está em constante evolução e acompanha as diversas transformações das realidades humanas, sendo necessário estabelecer regramentos no sentido de ordenar as constantes evoluções da sociedade, aproximando-as das vivências e dos valores, não esquecendo do sentido ético que repousa na nossa noção sobre a humanidade.

O direito pode ser visto como o reflexo de um processo no qual as pessoas buscam criar uma solução para o funcionamento e o convívio em sociedade. Consequentemente, o modelo idealizado fundamenta-se em valores e objetivos imediatos, a médio ou longo prazo, para o qual dispõe de um conjunto institucionalizado de órgãos e regras procedimentais.

Certamente, a dignidade humana, a vida e a segurança são alguns dos valores mais importantes e vem protegidos através da normatividade nacional e internacional com relação aos problemas humanitários e, em particular, ao problema do refúgio.

Por esta razão deve-se primar pelo amparo às pessoas em qualquer circunstância ou diante de qualquer tragédia, sendo essencial que se busque a efetividade dos direitos fundamentais e dos princípios dignidade da pessoa humana e da solidariedade.

Diante de todo o exposto, conclui-se que muitos refugiados encontram-se, hoje, vivendo em situações precárias, à espera de um local para iniciar uma nova vida, com uma dignidade humana flagrantemente desrespeitada, ante as condições precárias em que vivem e o desinteresse das autoridades em melhorar suas condições de vida, pois tratam-se, apenas, de vítimas de uma guerra. A supressão de tão relevante direito perdura até a atualidade, mesmo após a saída de sua nação, mas iniciou-seno momento em que o próprio país de origem não 
lhes garantiu o mínimo de valorização como seres humanos. Esta situação, somada aos crimes de guerra praticados no local de conflito, alcançando a viagem sofrida da fuga e sua situação de suporte deficitário nos países receptores, torna flagrante o desrespeito aos refugiados e a falta de uma vida digna.

\section{REFERÊNCIAS}

ACNUR. Falta de recursos ameaça ajuda a refugiados sírios no Líbano. Disponível em: <http:// www.acnur.org/t3/portu gues/noti cias/noticia/falta-de-recursosameaca-ajuda-a-refugiados-sirios-no-libano/>. Acesso em: 12 abr. 2018.

ACNUR. O que é a Convenção de 1951?. Disponível em: <http://www.acnur.org/portugues/informacao-geral/o-que-e-a-convencao-de-1951/>. Acesso em: 22 mar. 2018.

AHLERT, Mara; ALMEIDA Alcione. A inclusão social das pessoas na condição de refugiado no Brasil à luz dos direitos humanos. Disponível em: $<\mathrm{https}$ ://online.unisc .br/seer/index.php/barbaroi/article/view/9574>. Acesso em: 17 abr. 2018.

AMAL, Victor Wolfgang Kegel. A derrota da primavera Árabe e a crise dos refugiados na europa. Disponível em: <https://esquerdaonline.com.br/2017/02/05/a-derrota-da-primavera-arabe-e-a-crise-dos-refugia dos-na-europa/>. Acesso em: 22 mar. 2018.

CAMPOS, Lucien Vilhalva de. A guerra civil na Síria e seus refugiados: uma reflexão sobre a atuação do alto comissariado das nações unidas para os refugiados (ACNUR). Disponível em: <https://riuni.Unisul.br/bitstream/ handle/12345/1720/109230_Lucien.pdf? sequence=1\&isAllowed=y>. Acesso em: 22 mar. 2018.

DICIONÁRIO. Dicionário da língua portuguesa. Disponível em: $<$ https://www.priberam. pt/dlpo/refugiados $>$. Acesso em: 18 mar. 2018.

DUTRA, Katia. Primavera Árabe. Disponível em: <http://redes.moderna.com.br/tag/ primavera-arabe/>. Acesso em: 18 mar. 2018.

FURTADO, Gabriela; RODER, Henrique; AGUILAR, Sergio L. C. A guerra civil SÍRIA, o oriente médio e o sistema internacional. Disponível em: $<$ https://www.marilia .unesp.br/Home/Extensao/observatoriodeconflitosinternacionais/a-guerra-civil-siria. pdf>. Acesso em: 24 mar. 2018.

GARCIA, Vivilene. A guerra civil da Síria e a sua relação com o direito internacional público. Disponível em: <https://vivigarciaf.jusbrasil.com.br/artigos/416133712/a-guerra-civil-da-siria-e-a-sua-relacao-com-o-direito-internacional-publico $>$. Acesso em: 24 mar. 2018.

GUERRA, Sidney. Direitos humanos na ordem jurídica internacional e reflexos para ordem constitucional brasileira. 2. ed. São Paulo: Atlas, 2014.

JORNAL DA CULTURA. Humanidade e a guerra. Disponível em: < http://jornalcultura.sa po.ao/historia/a-humanidade-e-a-guerra/fotos>. Acesso em: 24 mar. 2018.

KANT, Immanuel. Fundamentação da metafísica dos costumes e outros escritos. Tradução de Leopoldo Holzbach, São Paulo: Martin Claret, 2004. 
MENDES, Gustavo Catunda. A tutela jurídica dos refugiados no direito brasileiro e internacional. Disponível em: $<$ http://www.acnur.org/fileadmin/scripts/doc.php?file=filead min/Documentos/portugues/BDL/Convencao_relativa_ao_Estatuto_dos_Refugiados>. Acesso em: 27 mar. 2018.

NASCIMENTO, Jhonatan. Geografia contemporânea: a primavera Árabe. Disponível em: <http:/geogra fiacontemporanea.blogspot.com.br/2011/10/primaveraarabe. html>. Acesso em: 17 mar. 2018.

REIS, Rossana Rocha; MENEZES, Thais Silva. Direitos humanos e refúgio: uma análise sobre o momento anterior à determinação do status de refugiado. Rev. Sociol. Polit., v. 22, n. 49, p. 61-83, mar. 2014. Disponível em: <http://www.scielo.br/pdf/rsocp/ v22n49/04.pdf>. Acesso em: 30 maio 2018.

SANTOS, Sofia José. À lupa: a guerra na Síria. Disponível em: <http://www.ces.uc.pt/ myces/UserFiles/livros/1097_\%C0\%20lupaGuerra\%20na\%20S\%EDria.SofiaJoseSantos.RedeAngola.Feveiro2014.pdf>. Acesso em: 22 maio 2018.

SOUZA, Carlos Eduardo Cardoso; PEIXOTO, Diego Madureira; CORREA, Flávio Barros; CISCOTTO, Renato Moreira; SANTOS, Walter Augusto Magalhães. A guerra civil na Síria: atores internos, jogos de poder e possíveis reflexos para o Brasil a partir da situação dos refugiados desse conflito. Disponível em: <:https://www.defesa.gov. br/arquivos/ensino_e_pesquisa/defesa_academia/cadn/artigos/xiv_cadn/a_guerra_civil_na_siria.pdf $>$. Acesso em: 30 maio 2018.

Recebido em: 30/05/2018 Aprovado em: 13/08/2018 